\title{
The Use of Nephrotoxic Medicament in Family Medicine
}

\author{
${ }^{1}$ Internal Medicine Specialist - Nephrologist, Clinic for Neophrology and Hemodialysis UCCK, Kosovo \\ ${ }^{2}$ Resident of Internal Medicine Clinic of Nephrology and Hemodialysis, UCCK Kosovo Hospital, Kosovo \\ ${ }^{3}$ Specialist of family medicine, Family Medicine Center, Kosovo \\ ${ }^{4}$ University of Pristina, Kosovo
}

Ibrahim Rudhani*1, Ahmet Avdullahu ${ }^{1}$, Naim Morina ${ }^{2}$, Azem Spahiu ${ }^{3}$, Lirim Spahiu ${ }^{4}$ and Pajtesa Kryeziu ${ }^{4}$

Received: March 03, 2018; Published: March 27, 2018

*Corresponding author: Naim Morina, Resident of Internal Medicine Clinic of Nephrology and Hemodialysis UCCK Kosovo Hospital Circle n. 10000 Pristina, Kosovo, Tel: GSM: +37744320307

\begin{abstract}
The purpose of this paper is to investigate the cases in which the nephrotoxic medicaments analyzed in this paper have been prescribed and the expression of the nephrotoxic side effects to the patients.Prospective method was used for this work. The study included 5076 patients, which 1437 were treated with nephrotoxic medicament such as Diclofenac, Gentamicin, Brufen, Sulidamor, etc, during the period December 1, 2016 to May 31, 2017 at the Family Medicine Center in Rogane- Kamenicë. Out of 5076 patients in the period December 2016 to May 2017, 1438 patients were treated with nephrotoxic medicament analyzed in this paper, which 571 were male and 867 female. 34 had symptoms of kidney damage, and 3 of them exposed dialysis. This study shows that the nephrotoxic medicament analyzed in this paper were prescribed in primary care with a prevalence of $28 \%$, predominating females by $60 \%$ compared to $40 \%$ in masculinity. From this study it emerges that these medicament had nephrotoxic effects to patients treated with a prevalence of $3.2 \%$.
\end{abstract}

Keywords: Kidney; Nephrotoxic medicament; Dialysi

\section{Introduction}

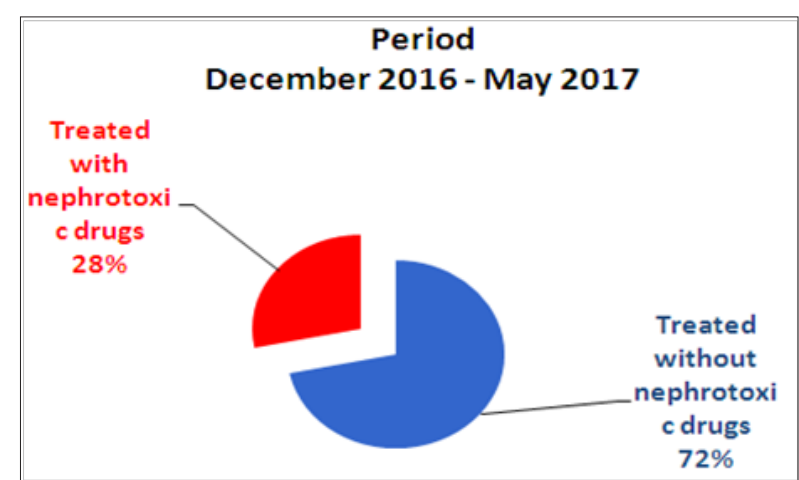

Figure 1: The number of treatments with nephrotoxic drugs.

Kidney is an essential organ of body that performs some important functions, including the maintenance of homeostasis, endocrine function, regulation of the extracellular environment, such as [1]. Detoxification and secretion of metabolites and toxic medicament. Therefore, the kidney is considered to be the main target organ of medicament (Figure 1). Kidney disease is considered a public health problem worldwide. They can become chronic and increase the cost of health care. In addition, they contribute to about
850,000 deaths every year, being the number 12 of deaths [2]. Population aging and advanced life expectancy have contributed to the spread of chronic diseases, including chronic kidney disease (Table 1). Addition, people may develop acute kidney damage (AKI), which is associated with various causes, such as burns, shock, medicamnet toxicity, sepsis, trauma, and so on.

Table 1: The Number of Treatments with Nephrotoxic Drugs.

\begin{tabular}{|c|c|}
\hline \multicolumn{2}{|c|}{ Number of treatments with nephrotoxic drugs } \\
\hline Treated without nephrotoxic medicament & 3638 \\
\hline Treated with nephrotoxic medicament & 1437 \\
\hline Total & 5076 \\
\hline
\end{tabular}

Approximately $20 \%$ of acute kidney damage is induced by medicament, but the treatment of old people increases the incidence of nephrotoxicity by (Table 2). up to 65\%. Kidney damage types which are stimulated by [3]. Medicament includes disorders of intraglomerular hemodynamics, tubular cell toxicity, inflammation, crystal nephropathy, rhabdomyolysis and thrombotic microangiopathy [4]. Medicament classes that are most involved in acute kidney injuries are antibiotics, non-steroidal anti-inflammatory medicament (NSAIDs), angiotensin converting 
enzyme inhibitors (ACE inhibitors) and contrasts (Figure 2). Due to the risks associated with the use of these medicaments, they should be carefully prescribed and dose recommendations should be followed strictly [5]. Diagnosing nephrotoxicity can be done through simple blood tests.

Table 2: Patients Treated with Nephrotoxic Drugs by Month.

\begin{tabular}{|c|c|c|c|c|c|}
\hline & Diclofenac & Gentamicin & Brufen & Sulidamor & Others \\
\hline December & 178 & 94 & 38 & 27 & 25 \\
\hline January & 152 & 67 & 26 & 26 & 26 \\
\hline February & 116 & 38 & 28 & 22 & 20 \\
\hline March & 100 & 45 & 24 & 16 & 20 \\
\hline April & 89 & 52 & 22 & 16 & 8 \\
\hline May & 90 & 33 & 15 & 11 & 13 \\
\hline
\end{tabular}

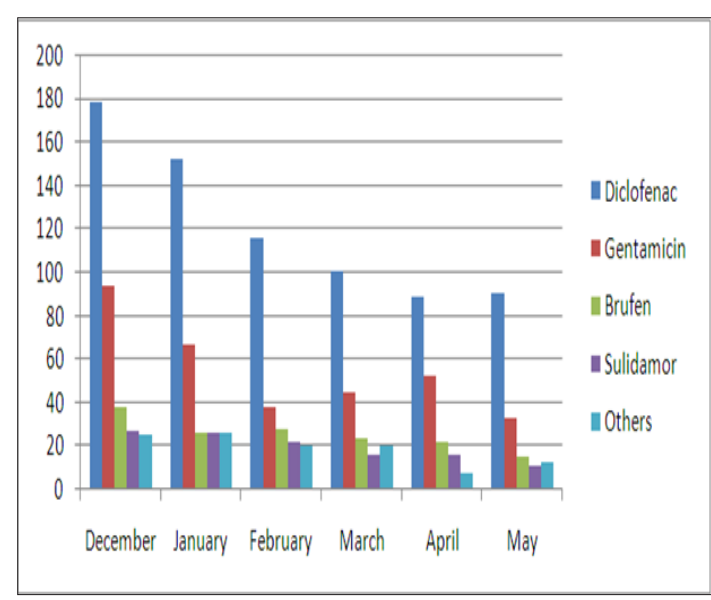

Figure 2: Patients treated with nephrotoxic drugs by month.

Evaluation of nephrotoxicity through blood tests involves measuring uric acid, Creatinine serum concentration, glomerular filtration rate, and Creatinine and diuretic clearance. Despite the large number of medications available today, it is necessary to use rational medicament to prevent adverse side effects, especially in such vital organs as kidney [6]. The identification of high risk patients and the rapid recognition of medicament related to injury syndrome with immediate termination of that drug, it is the key to managing such a case before it causes permanent damage to the renal tissue

(Table 3). In patients with critical illness, even small changes in kidney function can have undesirable results [7]. Kidney dysfunction caused by medicament is common in patients with critical illness for many reasons, including the coexistence of risk factors for acute kidney damage such as hypotension, sepsis, multiple medication and so on (Figure 3).

Table 3: Patients by Gender.

\begin{tabular}{|c|c|}
\hline \multicolumn{2}{|c|}{ Patients by Gender } \\
\hline Male & 570 \\
\hline Female & 867 \\
\hline Total & 1437 \\
\hline
\end{tabular}

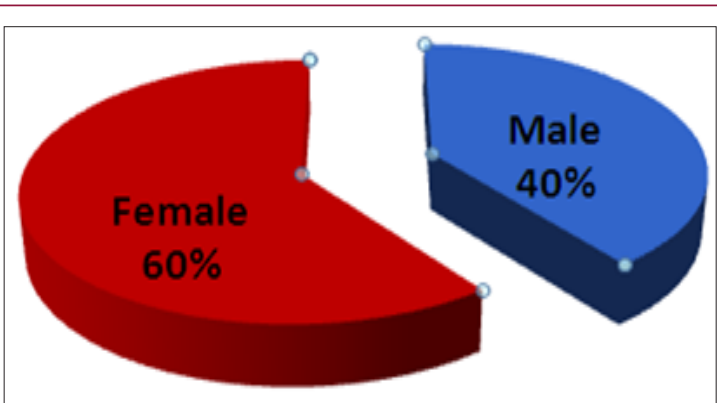

Figure 3: Patients by Gender.

\section{Research Aim}

The aim of this paper is to investigate the effects of nephrotoxic medicament prescribed in primary care as well as the appearance of these effects [8] on the basis of the sex and age of the patients and the expression of the nephrotoxic side effects in the researched patients (Table 4).

Table 4: Patients with Kidney Problems by Month.

\begin{tabular}{|c|c|}
\hline \multicolumn{2}{|c|}{ Patients with Kidney Problems by Month } \\
\hline December & 362 \\
\hline January & 297 \\
\hline February & 224 \\
\hline March & 205 \\
\hline April & 187 \\
\hline May & 162 \\
\hline
\end{tabular}

\section{Research Methodology}

To conduct this research prospective method was used [9]. The data was collected by all patients treated with nephrotoxic medicament at the Family Medicine Center in Rogana, Kamenicë during the period December 1, 2016 to May 31, 2017. Out of 5076 patients who sought assistance at the Family Medicine Center in Rogana, Kamenicë, 1437 of them were treated with nephrotoxic medicament. These data were supplemented by the Clinic of Nephrology at the University Clinical Center of Kosovo (UCCK) [10]. There were conducted hematological and biochemical laboratory analyzes and were analyzed by statistical methods (Figure 4).

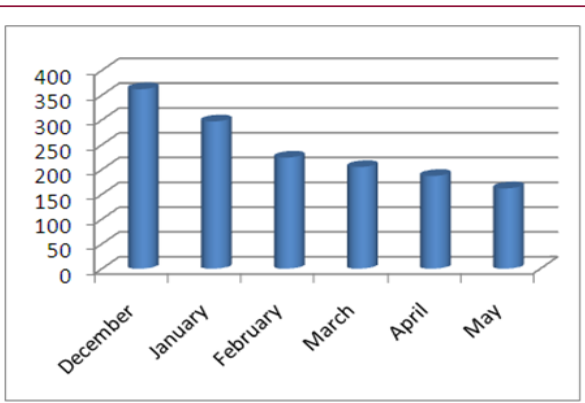

Figure 4: Patients with kidney problems by month.

\section{Results}

Out of 5076 patients who sought assistance at the Family Medicine Center in Rogana, Kamenicë, 1437 of them were treated with nephrotoxic medicament, with a $28 \%$ share of the total 
number [11]. From the data below we can conclude that the most prescribed monthly medication is Diclofenac, then Gentamicin, Brufen and others. The month when analyzed medicaments were mostly prescribed was December [12]. Of the total of 1437 cases treated with the analyzed medicament can be seen that the most are used in females with 867 cases, compared with the male gender with 570 cases, where expressed in percentage it turns out that $60 \%$ are women while $40 \%$ are males (Figure 5). From the research conducted for the period December 2016 to May 2017, we conclude that in December most of the nephrotoxic medicaments were prescribed. There were 362 cases [13]. Following in January 297 cases, February 224 cases, March 205, April 187 and May with 162 cases.

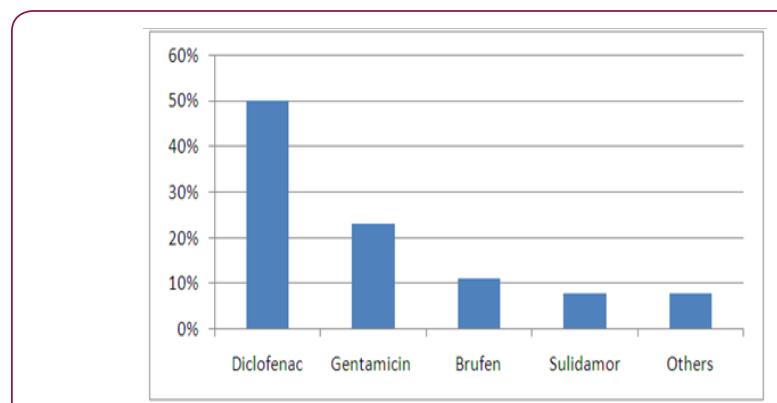

Figure 5: Nephrotoxic drugs given during this period expressed in percentage.

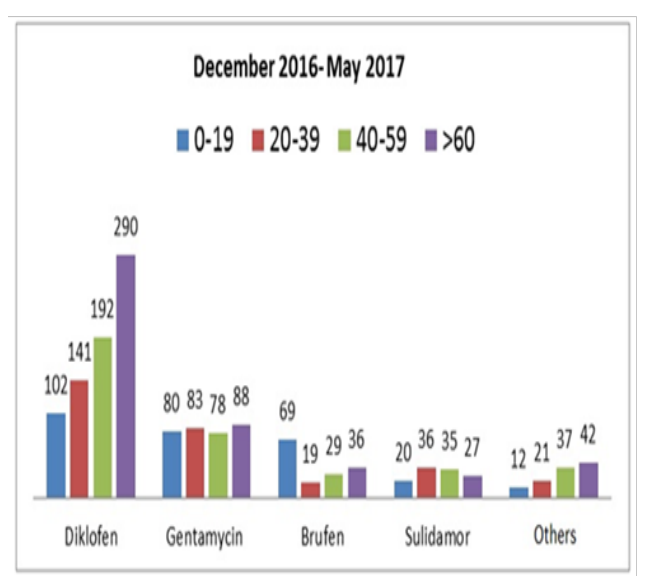

Figure 6: Application of nephrotoxic drugs by age.

The most prescribed medicament is [14]. Diclofenac with $50 \%$, Gentamicin 23\%, Brufen $11 \%$, Sulidamor $8 \%$, and other medicaments $8 \%$ (Table 5). Nephrotoxic Drugs given during this period [15]. Expressed in percentage during this research we have also found that these nephrotoxic medicament are mostly prescribed at age 60 [16]. With the exception of Burden which appears to [17]. Be mostly prescribed at ages of $0-19$, as well as Sulidamor to ages 20-39 years (Figure 6). Application of nephrotoxic drugs by age in this study, out of 1437 patients treated with the above medicaments, after about a week after treatment 34 of [18]. They have sought medical help due to fatigue, apathy, urinary problems [19]. After clinical and laboratory examinations, 31 patients had a change in laboratory analysis values such as blood, nitrogen, and transaminase. The Table 6 below shows the average values of the above mentioned analyzes. To these 31 patients, [20]. After the conservative treatment was normalized the value of the laboratory analysis and at the same time improved the clinical condition.

Table 5: Nephrotoxic Drugs Given During This Period Expressed in Percentage.

\begin{tabular}{|c|c|}
\hline \multicolumn{2}{|c|}{$\begin{array}{c}\text { Nephrotoxic Drugs Given During This Period Expressed in } \\
\text { Percentage }\end{array}$} \\
\hline Diclofenac & $50 \%$ \\
\hline Gentamicin & $23 \%$ \\
\hline Brufen & $11 \%$ \\
\hline Sulidamor & $8 \%$ \\
\hline Others & $8 \%$ \\
\hline
\end{tabular}

Table 6: Laboratory analyzes of patients with nephrologic problems and control group.

\begin{tabular}{|c|c|c|}
\hline & Patients & Control group \\
\hline WBC & 10.2 & 7.2 \\
\hline RBC & 3.22 & 4.1 \\
\hline HGB & 10.12 & 138 \\
\hline Urea & 9.49 & 2.4 \\
\hline Kreatinina & 178.8 & 88 \\
\hline ALT & 48.38 & 13 \\
\hline AST & 39.75 & 15 \\
\hline
\end{tabular}

Three out of 34 patients were in bad condition [21]. Without breathing, fatigue, apathy, edema, as well as increased values of nitrogenous matter and transaminases (Table 7). These patients were sent to UCCK - Nephrology Clinic, Pristine, which is indicated the substitute therapy, Hem dialysis. Patient N.G Female 1958, started treatment with hem dialysis, where after three hemodialysis sessions normalized the values of the nitrogenous material and the function of the kidney was restored. Patient F.C 1978 needed 5 hem dialysis sessions for normalization. Patient A.M 1981 male [22]. Because of bad condition needed 20 hem dialysis sessions and then the health condition was normalized. The table below shows the average values of the above mentioned analyzes [23].

Table 7: Laboratory analysis values in patients treated with hemodialysis.

\begin{tabular}{|c|c|c|}
\hline & Patients & Control group \\
\hline WBC & 10.5 & 7.2 \\
\hline RBC & 3.02 & 4.1 \\
\hline HGB & 9.8 & 13.8 \\
\hline Urea & 25.49 & 2.4 \\
\hline Creatinine & 662.8 & 88 \\
\hline ALT & 56.38 & 13 \\
\hline AST & 47.75 & 15 \\
\hline
\end{tabular}

\section{Conclusion}

From this research we can conclude that $28 \%$ of medicaments applied in Family Medicine belong to nephrotoxic medicaments. The most commonly prescribed medicaments were [24]. Diclofenac 
(50\%), Gentamicin (23\%), Ibuprofen (11\%), Nimesulide (8\%), and others (8\%), Diclofenac as a Nephrotoxic medicament was prescribed more to 60 years patients, ibuprofen 0-19, Nimesulide 20-39. Gender ratio: female gender [25]. (60\%) male gender (40\%). The month with the most prescribed nephrotoxic medicament was December. Out of 1437 cases where nephrotoxic medicaments have been prescribed, 37 patients have been exposed to kidney problems, while 3 of them have undergone treatment for hemodialysis due to acute renal insufficiency [26].

\section{Recommendation}

Based on the results of the study, we recommend that during the application of nephrotoxic medicament, kidney and liver function should be monitored. It is also necessary that the dose be adapted to the Creatinine clearance, especially to elderly people and those with chronic kidney disease.

\section{References}

1. Nasri H (2014) World kidney day. Chronic kidney disease and aging: A global health alert Iran J.Public Health 43(1): 126-127.

2. Schieppati A, Remuzzi G (2005) Chronic renal diseases as a public health problem: Epidemiology, social, and economic implications. Kidney Int Suppl (98): 7-10.

3. Jha V, Chugh KS (1995) Drug induced renal disease. J Assoc Physicians India 43(6): 407-421.

4. Taber SS, Mueller BA (2006) Drug-associated renal dysfunction. Crit Care Clin 22(2): 357-374.

5. Singh NP, Ganguli A, Prakash A (2003) Drug-induced kidney diseases. J Assoc Phys India 51: 970-979.

6. Nolin TD, Himmelfarb J (2010) Mechanisms of drug-induced nephrotoxicity. Handb Exp Pharmacol (196): 111-130.

7. Perazella MA (2005 ) Drug-induced nephropathy: an update. Expert Opin Drug Saf 4(4): 689-706.

8. Naughton CA (2008) Drug-induced nephrotoxicity. Am Fam Physician b78 (6): 743-750.

9. Schetz M, Dasta J, Goldstein S, Golper T (2005) Drug-induced acute kidney injury. Curr Opin Crit Care 11(6): 555- 565.

10. Schnellmann RG, Kelly KJ (1999) Pathophysiology of nephrotoxic acute renal failure. In: Berl T, Bonventre JV (Eds.), Acute Renal Failure. Philadelphia, Blackwell Science; Atlas of Diseases of the Kidney, USA.

11. Perazella MA (2005) Drug-induced nephropathy: an update. Expert Opin Drug Saf 4(4): 689-706.

This work is licensed under Creative Commons Attribution 4.0 License

Submission Link: https://biomedres.us/submit-manuscript.php
12. Markowitz GS, Perazella MA (2005) Drug-induced renal failure: a focus on tubulointerstitial disease. Clin Chim Acta 351(1-2): 31-47.

13. Coco TJ, Klasner AE (2004) Drug-induced rhabdomyolysis. Curr Opin Pediatr 16(2):206-210.

14. Pisoni R, Ruggenenti P, Remuzzi G (2001) Drug-induced thrombotic micro- angiopathy: incidence, prevention and management. Drug Saf 24(7): 491-501.

15. Luft FC (1984) Clinical significance of renal changes engendered by aminoglycosides in man. J Antimicrob Chemother13(1): 23-30.

16. Sorrell TC, Collignon PJ (1985) A prospective study of adverse reactions associated with vancomycin therapy. J Antimicrob Chemother 16(2): 235-241.

17. Farber BF, Moellering RC Jr (1983) Retrospective study of toxicity of preparations of vancomycin from 1974 to 1981. Antimicrob Agents Chemother 23(1):138-141.

18. Krieble BF, Rudy DW, Glick MR, Clayman MD (1993) Case report : Acyclovir neurotoxicity and nephrotoxicity - a role for hemodialysis. Am J Med Sci 305(1): 36-39.

19. Guo X, Nzerue C (2002) How to prevent, recognize, and treat druginduced nephrotoxicity. Cleve Clin J Med 69(4): 289-90.

20. Cockcroft DW, Gault MH (1976) Prediction of creatinine clearance from serum creatinine. Nephron 16(1): 31-41.

21. Schwartz GJ, Haycock GB, Edelmann CM, Spitzer A (1976) A simple estimate of glomerular filtration rate in children derived from body length and plasma creatinine. Pediatrics 58(2): 259-263.

22. Fuchs TC, Hewitt P (2011) Biomarkers for drug-induced renal damage and nephrotoxicity-an overview for applied toxicology. AAPS J 13(4): 615-631.

23. Kaufman J, Dhakal M, Patel B, Hamburger R (1991) Communityacquired acute renal failure. Am J Kidney Dis 17(2): 191-198.

24. Schoolwerth AC, Sica DA, Ballermann BJ, Wilcox CS (2001) Renal considerations in angiotensin converting enzyme inhibitor therapy: a statement for healthcare professionals from the Council on the Kidney in Cardiovascular Disease and the Council for High Blood Pressure Research of the American Heart Association. Circulation. 104(16): 19851991.

25. Fry AC, Farrington K (2006) Management of acute renal failure. Postgrad Med J 82(964): 106-116.

26. Alex M Davison, J Stewart Cameron, Jean-Pierre Grünfeld, Eberhard Ritz, Claudio Ponticelli, et al. (2014) Nefrologjia klinike. Traktat i Oksfordit Vëllimi.

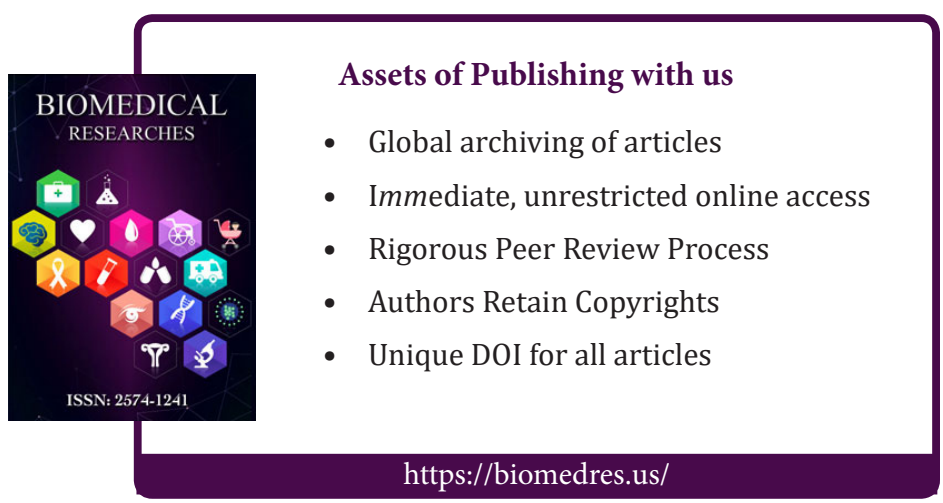

